\title{
Case Report \\ Central Venous Catheter-Related Tachycardia in the Newborn: Case Report and Literature Review
}

\author{
Aya Amer, Roland S. Broadbent, Liza Edmonds, and Benjamin J. Wheeler \\ Department of Women's and Children's Health, University of Otago, Dunedin School of Medicine, P.O. Box 56, \\ Dunedin 9054, New Zealand \\ Correspondence should be addressed to Benjamin J. Wheeler; ben.wheeler@otago.ac.nz
}

Received 28 August 2016; Accepted 15 November 2016

Academic Editor: Frans J. Walther

Copyright (C) 2016 Aya Amer et al. This is an open access article distributed under the Creative Commons Attribution License, which permits unrestricted use, distribution, and reproduction in any medium, provided the original work is properly cited.

Central venous access is an important aspect of neonatal intensive care management. Malpositioned central catheters have been reported to induce cardiac tachyarrhythmia in adult populations and there are case reports within the neonatal population. We present a case of a preterm neonate with a preexisting umbilical venous catheter (UVC), who then developed a supraventricular tachycardia (SVT). This was initially treated with intravenous adenosine with transient reversion. Catheter migration was subsequently detected, with the UVC tip located within the heart. Upon withdrawal of the UVC and a final dose of adenosine, the arrhythmia permanently resolved. Our literature review confirms that tachyarrhythmia is a rare but recognised neonatal complication of malpositioned central venous catheters. We recommend the immediate investigation of central catheter position when managing neonatal tachyarrhythmia, as catheter repositioning is an essential aspect of management.

\section{Introduction}

Obtaining central venous access, often via an umbilical venous catheter (UVC), is a common aspect of modern NICU care and allows for the reliable administration of fluid, nutrition, and essential medications to unwell neonates. Despite these benefits, complications can occur, often related to malposition, extravasation, and/or thrombosis $[1,2]$. Resultant cardiac complications are rare but potentially life threatening [2]. In contrast, tachyarrhythmias, such as supraventricular tachycardia (SVT), are relatively common in neonates [3], but their occurrence as a complication of central venous access, particularly in association with prematurity, is not often seen or considered.

We present a case of SVT secondary to UVC migration and malposition in a 29 -week gestation neonate and review the available literature. We conclude with a suggested approach to the evaluation, management, and prevention of neonatal tachyarrhythmias occurring in the context of central venous access.

\section{Case Report}

A $1240 \mathrm{~g}$ (50th centile), 29-week gestation male twin (twin 2) was born following a pregnancy complicated by twin-to-twin transfusion (recipient twin). Delivery was via emergency lower segment caesarean section, due to foetal distress. Apgar scores at birth were 2 ( 1 minute), 6 (5 minutes), and 8 (10 minutes). Initial resuscitation included intubation and ventilation, as well as cardiac compressions for the first 2 minutes because of a sustained heart rate of less than 60 beats/minute. His subsequent management included surfactant administration, empiric antibiotics, caffeine, and conventional mechanical ventilation for 12 hours before being extubated onto Continuous Positive Airway Pressure (CPAP). In addition, as a routine part of NICU care, a 3.5 French double lumen UVC was inserted to a length of $7 \mathrm{~cm}$. It was noted to be bleeding back easily, and an anteriorposterior (AP) chest X-ray (CXR) confirmed the catheter tip in a satisfactory position at $\mathrm{T} 9$, just below the diaphragm; see Figure 1. 


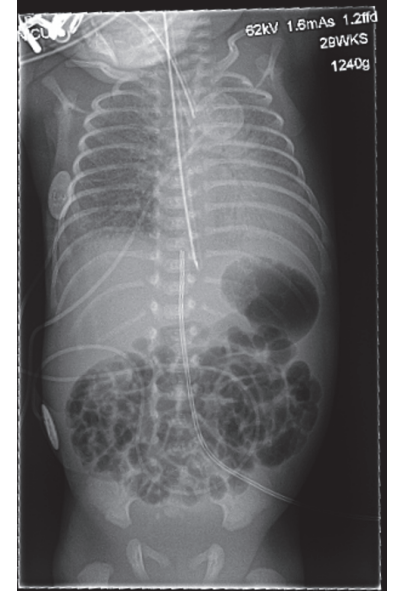

FIGURE 1: Initial postinsertion CXR, showing appropriate UVC placement, just below the diaphragm at T9.

At 30 hours of age, he developed sudden onset tachycardia, with a heart rate of 250-270 beats/minute. He remained well perfused, with no respiratory or haemodynamic compromise. Mean arterial blood pressure (MABP) was $31 \mathrm{mmHg}$. An electrocardiogram (ECG) was diagnostic for SVT, demonstrating a narrow complex tachycardia with a rate of 259 beats/minute, a normal QTc of $303 \mathrm{~ms}$, absent p-waves, and no flutter waves; see Figure 2.

Vagal manoeuvres were ineffective. Adenosine was then administered starting with a dose of $50 \mathrm{mcg} / \mathrm{kg}$, followed by $100 \mathrm{mcg} / \mathrm{kg}$. Following a third dose $(150 \mathrm{mcg} / \mathrm{kg})$ he reverted to sinus rhythm. However, 20 minutes later SVT returned. This sequence (recurrent SVT and then nonsustained response to adenosine) repeated itself twice over the next 45 minutes with subsequent doses of adenosine, given at incrementally increasing doses of $50 \mathrm{mcg} / \mathrm{kg}$ to a maximum of $300 \mathrm{mcg} / \mathrm{kg}$. While this was occurring, AP and lateral CXRs were performed to assess the UVC position. These demonstrated migration of the UVC tip into the right atrium; see Figure 3.

The UVC was pulled back $1 \mathrm{~cm}$ under aseptic technique. At this point a final dose of adenosine $(300 \mathrm{mcg} / \mathrm{kg})$ was given which resulted in permanent reversion to sinus rhythm.

Throughout these events the infant had no evidence of cardiovascular compromise. His MABP remained stable at $35 \mathrm{mmHg}$. He however did require a small temporary increase in his oxygen requirement. After 11 weeks he was discharged home without any cardiovascular concerns or sequelae.

\section{Discussion}

We have described the rare scenario of SVT as a consequence of UVC migration and malposition. While tachyarrhythmias are well recognised as a potential complication of central venous catheters in adults, only scattered case reports exist in the neonatal literature [3]. 16 cases of atrial tachyarrhythmia associated with central venous access in neonates are available

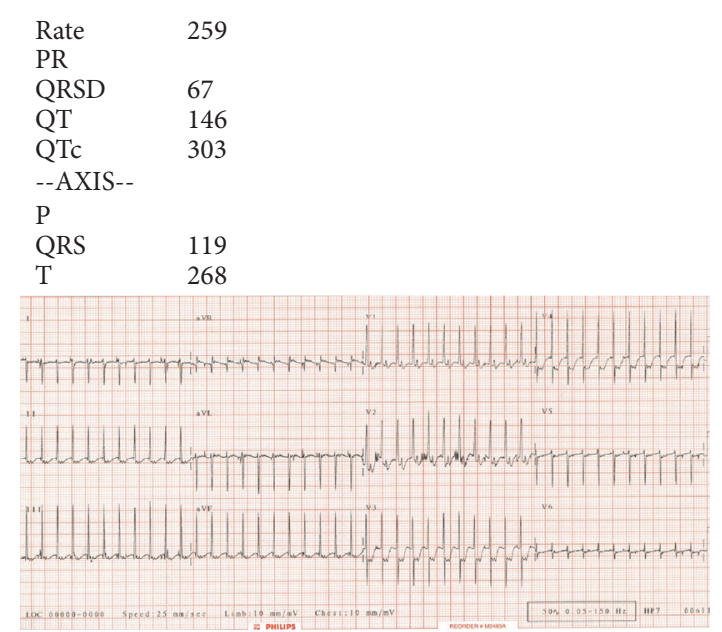

FIGURE 2: ECG demonstrating narrow complex tachycardia; rate: 260 beats/minute.

to review when combined with our case [1, 3-12]. These are presented in Table 1. Atrial flutter (8/16) and SVT (7/16) are the two common rhythms described. An awareness of this pattern is vital, as atrial flutter in a non-catheter-related context is less common than SVT and thus potentially prone to underrecognition [3]. Promptly and accurately distinguishing the type of arrhythmia is particularly important as treatment differs, with synchronised cardioversion for atrial flutter versus intravenous adenosine for SVT [1, 3-10, 12].

Migration of central venous catheters in neonates is well known in clinical practice but has not been well studied. Both Peripheral Inserted Central Catheters (PICCs) and UVCs are implicated, with a recent case series reporting migration in up to $23 \%$ of UVCs at 24 hours [13]. This migration may occur for a number of reasons, including contraction of the umbilical stump and changes in size of the abdomen (in the case of UVCs); recurrent movement of the affected limb or head; and routine flushing and handling of the catheter by nursing/medical staff. Therefore, correct initial positioning of the catheter tip upon insertion does not preclude the central line as a cause for a subsequent arrhythmia and serial imaging should be considered as a way of confirming catheter tip location. The validation of ultrasound for localisation of catheters tips is a welcome advance [1]. Understanding the potential for catheter migration and subsequent arrhythmia is also important as time to onset varies. While the majority occur at the time of insertion, arrhythmia can occur hours or even days after insertion (in one case, 47 days after insertion) $[6,9,11,12]$. This is demonstrated by our case, with migration of the catheter tip implicated in SVT onset more than a day after insertion.

There are several proposed mechanisms for arrhythmia induction. It could be that there are premature atrial beats induced when the catheter tip comes into contact with the endocardium, thus triggering an SVT in the presence of an accessory pathway [1]. Another possible mechanism is that the catheter could cause mechanical distortion of the atria, predisposing to the development of a reentry pathway [3]. 
TABLE 1: Reported cases of rapid atrial arrhythmias associated with central venous catheters in neonates.

\begin{tabular}{|c|c|c|c|c|c|c|}
\hline Author (year) & $\begin{array}{l}\text { Cases } \\
(n)\end{array}$ & Catheter type & Catheter position & $\begin{array}{c}\text { Interval between } \\
\text { insertion and onset of } \\
\text { arrhythmia }\end{array}$ & $\begin{array}{l}\text { Arrhythmia } \\
\text { type }\end{array}$ & Treatment \\
\hline $\begin{array}{l}\text { Dunnigan et al. } \\
\text { (1985) }\end{array}$ & 3 & UVC & Right atrium & $\begin{array}{l}\text { Day of insertion } \\
\text { (time not recorded) }\end{array}$ & Atrial flutter $\times 3$ & Transoesophageal pacing \\
\hline $\begin{array}{l}\text { Leroy et al. } \\
(2002)\end{array}$ & 1 & UVC & Left atrium & Time of insertion & Atrial flutter & Transoesophageal pacing \\
\hline $\begin{array}{l}\text { Sinha et al. } \\
(2005)\end{array}$ & 1 & UVC & $\begin{array}{l}\text { 5th thoracic } \\
\text { vertebra }\end{array}$ & Immediate & Atrial flutter & Synchronised cardioversion \\
\hline $\begin{array}{l}\text { Verheij et al. } \\
(2009)\end{array}$ & 2 & UVC & $\begin{array}{l}\text { 6th thoracic } \\
\text { vertebra } \\
7 \text { th thoracic } \\
\text { vertebra }\end{array}$ & Time of insertion $\times 2$ & $\begin{array}{l}\text { SVT } \\
\text { Atrial flutter }\end{array}$ & $\begin{array}{c}\text { Adenosine }{ }^{*} \\
\text { Synchronised cardioversion* }\end{array}$ \\
\hline $\begin{array}{l}\text { de Almeida et } \\
\text { al. (2016) }\end{array}$ & 1 & UVC & Left atrium & 12 hours & SVT & Synchronised cardioversion \\
\hline $\begin{array}{l}\text { Current case: } \\
\text { Amer et al. } \\
(2016)\end{array}$ & 1 & UVC & Right atrium & 30 hours & SVT & $\begin{array}{l}\text { Adenosine* } \\
\text { Catheter withdrawal }\end{array}$ \\
\hline $\begin{array}{l}\text { Obidi et al. } \\
(2006)\end{array}$ & 1 & PICC & Right atrium & 48 hours & Atrial flutter & Synchronised cardioversion \\
\hline $\begin{array}{l}\text { Thyoka et al. } \\
\text { (2014) }\end{array}$ & 1 & PICC & Right atrium & Day of insertion & SVT & Adenosine \\
\hline $\begin{array}{l}\text { Daniels et al. } \\
\text { (1984) }\end{array}$ & 2 & External jugular & Right atrium & $\begin{array}{l}\text { Time of insertion } \\
\text { Day } 47\end{array}$ & $\begin{array}{l}\text { SVT } \\
\text { Atrial flutter }\end{array}$ & Synchronised cardioversion* \\
\hline $\begin{array}{l}\text { Da Silva and } \\
\text { Waisberg } \\
(2010)\end{array}$ & 1 & External jugular & $\begin{array}{c}\text { Mid SVC } \\
\text { (withdrawn } 1 \mathrm{~cm} \text { ) }\end{array}$ & Time of insertion & SVT & Synchronised cardioversion \\
\hline $\begin{array}{l}\text { Conwell et al. } \\
\text { (1993) }\end{array}$ & 1 & Right femoral & Right atrium & 48 hours & $\begin{array}{l}\text { Ectopic atrial } \\
\text { tachycardia }\end{array}$ & Catheter withdrawn \\
\hline $\begin{array}{l}\text { Casta et al. } \\
(2008)\end{array}$ & 1 & Internal jugular & Mid SVC ${ }^{\ddagger}$ & Time of insertion & SVT & $\begin{array}{c}\text { Adenosine } \\
\text { Synchronised cardioversion }\end{array}$ \\
\hline
\end{tabular}

*: arrhythmia recurred prior to catheter tip being sufficiently withdrawn.

$\ddagger$ : arrhythmia thought to be due to transoesophageal echo probe, though internal jugular and femoral venous line were also present at this time.

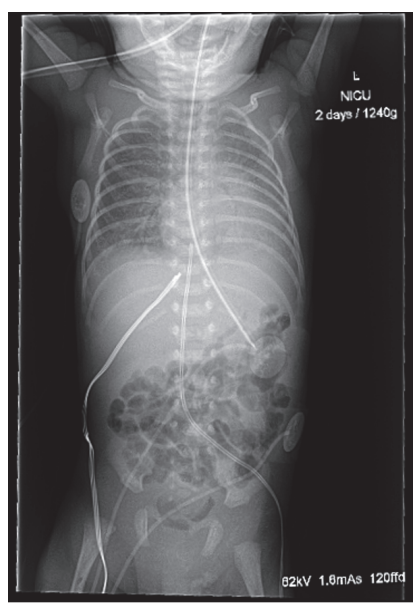

(a)

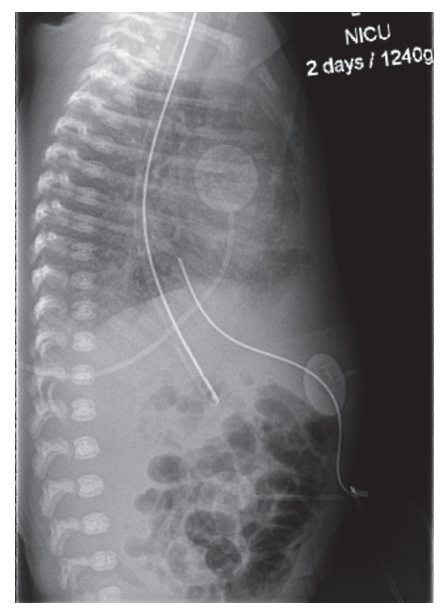

(b)

FIGURE 3: AP and lateral chest and abdomen X-rays taken after onset of SVT. The tip of the catheter is seen to have migrated into the right atrium. 
Either way, in the majority of cases catheter tip withdrawal appears important but alone may not induce reversion to sinus rhythm, with medical therapy also usually required. In all cases reported, once the catheter was removed or withdrawn to a satisfactory position \pm definitive medical therapy, there were no further recurrences of arrhythmia.

In conclusion, atrial tachyarrhythmia must be added to the range of dangerous complications of central indwelling catheters in the neonates. This report is intended to highlight this complication, raise awareness, and provide a more complete description of this rare adverse event. Confirmation of arrhythmia type (SVT versus atrial flutter) and determining catheter position are critical aspects of acute management. Withdrawal of the catheter to sit outside the heart should occur before cardioversion. This case is also a salient reminder that UVCs can migrate following their initial placement, and consideration should be given to serial catheter imaging as part of a program aimed at reducing catheter-related complications.

\section{Competing Interests}

The authors declare that they have no competing interests.

\section{References}

[1] G. Verheij, V. Smits-Wintjens, L. Rozendaal, N. Blom, F. Walther, and E. Lopriore, "Cardiac arrhythmias associated with umbilical venous catheterisation in neonates," BMJ Case Reports, vol. 2009, 2009.

[2] M. Restieaux, A. Maw, R. Broadbent, P. Jackson, D. Barker, and B. Wheeler, "Neonatal extravasation injury: prevention and management in Australia and New Zealand-a survey of current practice," BMC Pediatrics, vol. 13, article 34, 2013.

[3] P. S. L. Da Silva and J. Waisberg, "Induction of life-threatening supraventricular tachycardia during central venous catheter placement: an unusual complication," Journal of Pediatric Surgery, vol. 45, no. 8, pp. E13-E16, 2010.

[4] A. Dunnigan, W. Benson Jr., and D. G. Benditt, "Atrial flutter in infancy: diagnosis, clinical features, and treatment," Pediatrics, vol. 75, no. 4, pp. 725-729, 1985.

[5] M. Thyoka, I. Haq, and G. Hosie, "Supraventricular tachycardia precipitated by a peripherally inserted central catheter in an infant with gastroschisis," BMJ Case Reports, 2014.

[6] S. R. Daniels, D. W. Hannon, R. A. Meyer, and S. Kaplan, "Paroxysmal supraventricular tachycardia. A complication of jugular central venous catheters in neonates," American Journal of Diseases of Children, vol. 138, no. 5, pp. 474-475, 1984.

[7] V. Leroy, V. Belin, C. Farnoux et al., "A case of atrial flutter after umbilical venous catheterization," Archives de Pédiatrie, vol. 9, no. 2, pp. 147-150, 2002.

[8] A. Sinha, C. J. Fernandes, J. J. Kim, A. L. Fenrich Jr., and J. Enciso, "Atrial flutter following placement of an umbilical venous catheter," American Journal of Perinatology, vol. 22, no. 5, pp. 275-277, 2005.

[9] E. Obidi, P. Toubas, and J. Sharma, "Atrial flutter in a premature infant with a structurally normal heart," Journal of MaternalFetal and Neonatal Medicine, vol. 19, no. 2, pp. 113-114, 2006.

[10] A. Casta, D. W. Brown, and K. Yuki, "Induction of supraventricular tachycardia during transesophageal echocardiography: an unusual complication," Journal of Cardiothoracic and Vascular Anesthesia, vol. 22, no. 4, pp. 592-593, 2008.

[11] J. Conwell, M. Cocalis, and L. Erickson, "EAT to the beat: 'ectopic' atrial tachycardia caused by catheter whip," The Lancet, vol. 342, no. 8873, p. 740, 1993.

[12] M. M. de Almeida, W. G. Tavares, M. M. Furtado, and M. M. Fontenele, "Neonatal atrial flutter after the insertion of an intracardiac umbilical venous catheter," Revista Paulista de Pediatria: Orgão Oficial da Sociedade de Pediatria de São Paulo, vol. 34, no. 1, pp. 132-135, 2016.

[13] R. Gupta, A. L. Drendel, R. G. Hoffmann, C. V. Quijano, and M. R. Uhing, "Migration of central venous catheters in neonates: a radiographic assessment," American Journal of Perinatology, vol. 33, no. 6, pp. 600-604, 2016. 


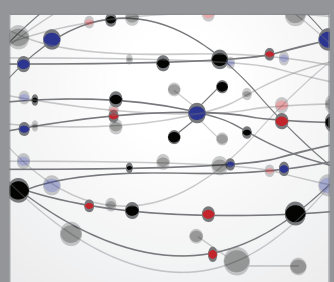

The Scientific World Journal
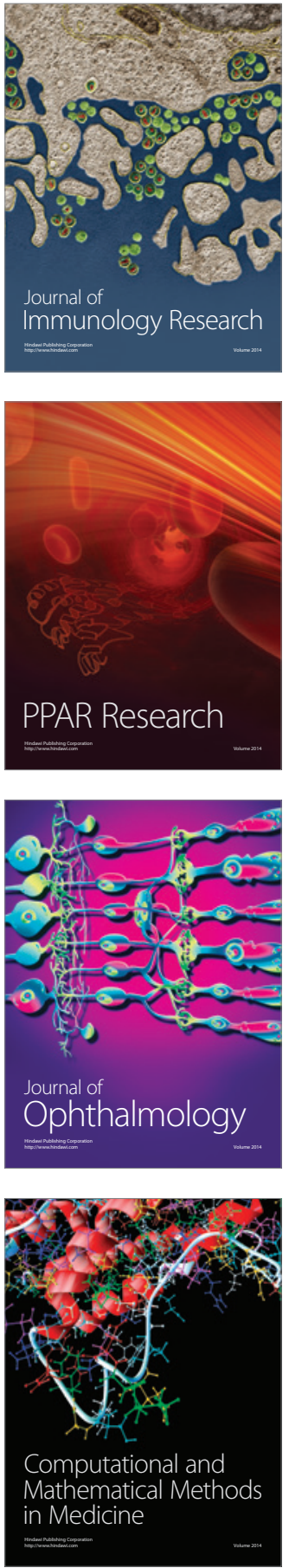

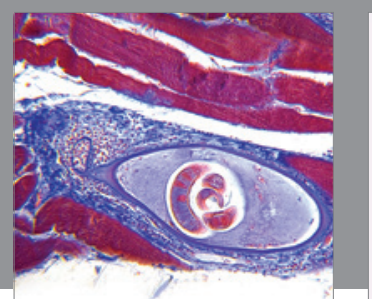

Gastroenterology Research and Practice

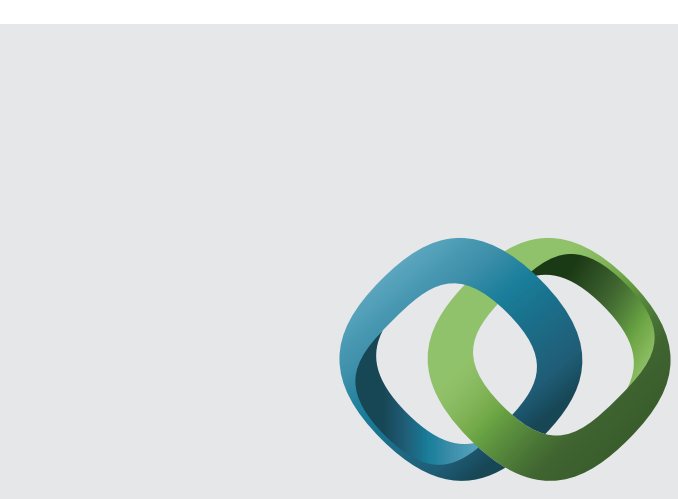

\section{Hindawi}

Submit your manuscripts at

http://www.hindawi.com
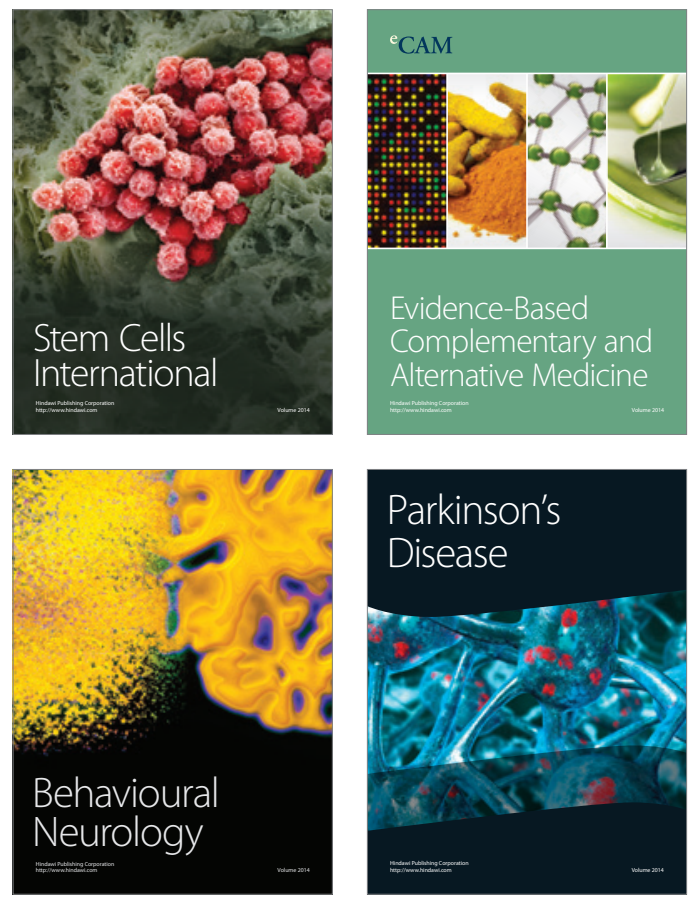
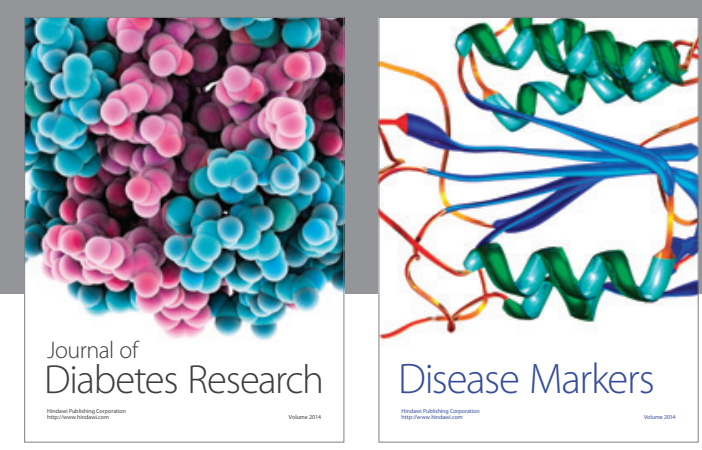

Disease Markers
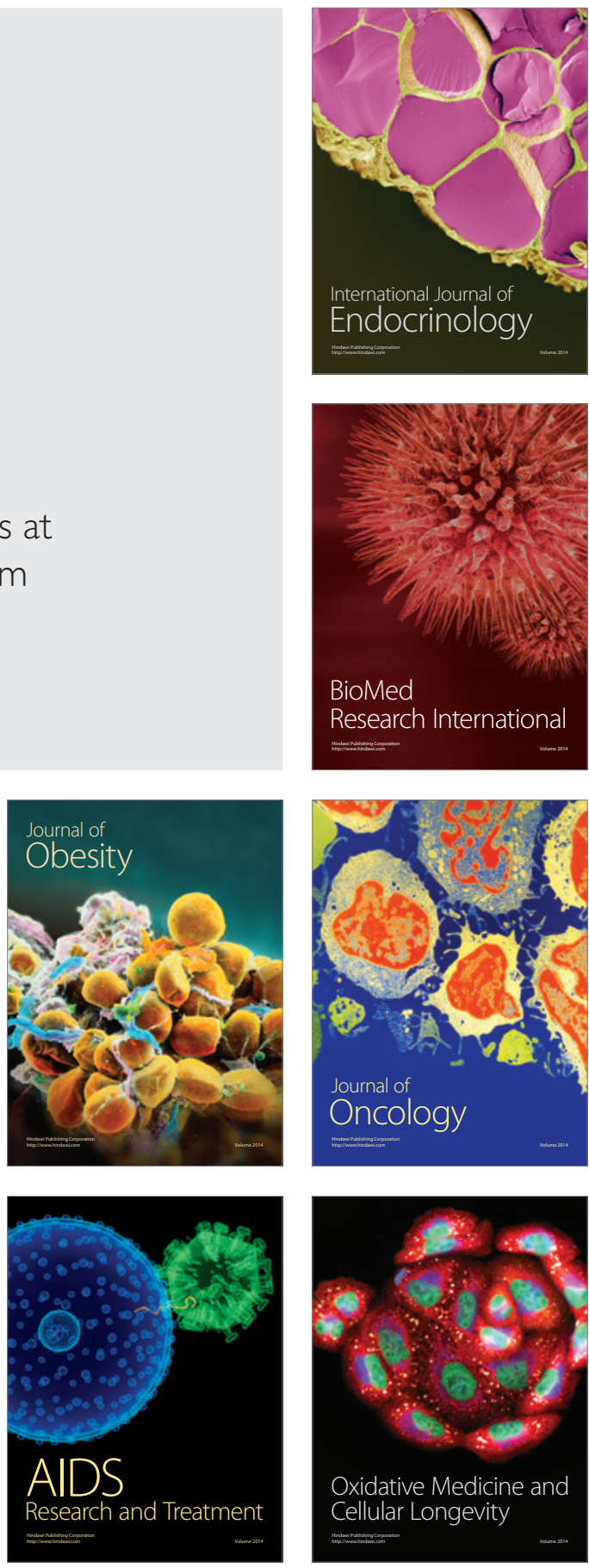